\section{P104 T HELPER 1 AND T HELPER 22 CELL RESPONSES AGAINST PSEUDOMONAS AERUGINOSA INFECTIONS}

doi:10.1136/thx.2010.150987.5

H K Bayes, T Evans. Division of Immunology, Infection and Inflammation, University of Glasgow, Glasgow, UK

Introduction Pseudomonas aeruginosa is an important opportunistic respiratory pathogen responsible for ventilator-associated pneumonia, acute lower respiratory tract infections in immunocompromised patients and chronic respiratory infections in cystic fibrosis. Antibody-mediated adaptive immune responses exist in cystic fibrosis patients but these lack protective opsonic activity. The role of $\mathrm{CD} 4^{+} \mathrm{T}$ cell responses to Pseudomonas remains unclear. Novel $\mathrm{T}$ helper (Th) cell subsets have also recently been defined; Th22 cells produce IL-22, whereas Th17 cells produce IL-17 cytokines in addition to IL-21 and IL-22. The properties of IL-22-producing CD4 ${ }^{+}$ cells in humans remains to be defined, but include an important respiratory anti-microbial defense function. Immunopathological roles of Th17/Th22 cells may also exist. We assessed T-helper cell responses to Pseudomonas in healthy adults.

Methods $\mathrm{CD}_{14}{ }^{+}$monocytes and memory $\mathrm{CD} 4{ }^{+} \mathrm{CD} 45 \mathrm{RO}{ }^{+} \mathrm{T}$ cells were isolated from peripheral blood using magnetic-activated cell sorting. Monocyte-derived dendritic cells (DCs) were generated by culture in the presence of IL-4 and GM-CSF. DCs were stimulated with live Pseudomonas aeruginosa strain PA103. DC activation markers, CD40 and CD86, were measured via flow cytometry. Autologous T cells were co-cultured with activated DCs, or their supernatants, for 6-days. T cell phenotype was analysed via flow cytometry and ELISA of supernatants for secreted cytokines. T cell incorporation of carboxyfluorescein-succinimidyl-ester was utilised to demonstrate cell multiplication.

Results We demonstrate that monocyte-derived DCs from healthy adults are readily activated by Pseudomonas. Co-culture of autologous memory $\mathrm{CD}^{+} \mathrm{T}$ cells with Pseudomonas-activated DCs resulted in $\mathrm{CD}^{+} \mathrm{T}$ cells primarily producing IFN-gamma, as well as T cell subsets expressing both IFN-gamma and IL-22, or IL-22 alone. No Th17 response to Pseudomonas was evident. The response was MHC-restricted and specific T cell proliferation was demonstrated. Reproducibility of the response within individuals was also shown. Conclusions These data demonstrate that healthy adults possess Th1 and Th22 memory cell responses to Pseudomonas aeruginosa. The results may have important implications for patients with deficits in cellular immunity and the pathogenesis of chronic pseudomonas infection in cystic fibrosis. Further work is required to ascertain cross-reactivity of response, antigenic triggers, and the role these cellular responses play in protection vs pathogenesis in Pseudomonal pulmonary infections.

\section{P105 BURKHOLDERIA LATENS-A NEW INFECTION IN CF PATIENTS}

doi:10.1136/thx.2010.150987.6

${ }^{1} \mathrm{~A}$ Horsley, ${ }^{2} \mathrm{C}$ Perry, ${ }^{2} \mathrm{~K}$ Martin, ${ }^{1} \mathrm{~K}$ Webb, ${ }^{2} \mathrm{D}$ Kenna, ${ }^{1} \mathrm{~A}$ Jones. ${ }^{1}$ Manchester Adult CF Centre, Manchester, UK; ${ }^{2} P H L S$, Colindale, London, UK

Background Burkholderia latens was first recognised as a novel species of the Burkholderia cepacia complex (Bcc) in 2008. To date, there are no reports of pulmonary infection. Here, we report a cluster of three CF patients all with chronic infection by $B$ latens, and all geographically linked.

Patient details Three patients have been identified as chronically infected with $B$ latens: a 23-year female ( $\mathrm{FEV}_{1} 23 \%$ predicted), a 23 year $\mathrm{M}\left(\mathrm{FEV}_{1} 55 \%\right)$, and a 26 -year female $\left(\mathrm{FEV}_{1} 37 \%\right)$. The first two live within 1 mile of each other, and had been known to be infected with $\mathrm{Bcc}$ since childhood, though the organism was only finally identified as $B$ latens in 2009. The third patient has been infected since May 2008, but had lived in the same town as the other patients until 2 years previously, and had attended the same paediatric centre.

Microbiology All $B$ latens isolates were confirmed by recA sequencing at the national reference laboratory (Colindale), and PFGE profiles showed $>90 \%$ similarity. Multiple isolates have been obtained from each of the three patients, and they are all considered chronically infected. Formal eradication has not been attempted.

Clinical impact Over the preceding 3 years, annual decline in $\mathrm{FEV}_{1}$ was $6.5 \%$ and $4.5 \%$ for the first two patients, though this deterioration was not attributed to Bcc. Annual decline in $\mathrm{FEV}_{1}$ for patient 3 was $1.5 \%$, with no significant change in spirometry, rate of decline in spirometry or weight following isolation of $B$ latens. There have been no cases of cepacia syndrome sepsis secondary to $B$ latens.

Summary This is the first report of chronic pulmonary infection by $B$ latens. All three subjects are geographically linked to the same town. The organism may come from a common environmental source, but cross infection cannot be ruled out. In this small sample there do not appear to have been any short-term unexpected adverse effects on lung health (patient 3), but it is not yet possible to infer the longer term effects of chronic $B$ latens infection.

\section{P106 INFLAMMATORY MARKERS: DATA FROM THE UK CF GENE THERAPY CONSORTIUM RUN-IN STUDY}

doi:10.1136/thx.2010.150987.7

${ }^{1} \mathrm{~J}$ A Innes, ${ }^{2} \mathrm{~J}$ Donovan, ${ }^{2} \mathrm{~S}$ Soussi, ${ }^{2} \mathrm{~N}$ Newman, ${ }^{1} \mathrm{~J}$ Leiton, ${ }^{1} \mathrm{~K}$ Campbell, ${ }^{1} \mathrm{~J}$ Gibson, ${ }^{1} \mathrm{~A}$ Doherty, ${ }^{2} \mathrm{E}$ W F W Alton, ${ }^{1} \mathrm{C}$ Boyd, ${ }^{2} \mathrm{U}$ Griesenbach, ${ }^{2} \mathrm{~J} \mathrm{C}$ Davies. ${ }^{1}$ Medical Genetics, Western General Hospital, Edinburgh, UK; ${ }^{2}$ Department of Gene Therapy, Imperial College, London, UK

Inflammatory markers in sputum and serum have been used with variable success as outcome measures in interventional studies. Limited data are available on reproducibility of such assays in cystic fibrosis (CF) particularly over a long time period. This study was designed to address this; stable patients $\left(\mathrm{FEV}_{1}>40,>10\right.$ years age) were recruited into the study which ran over an 18-month period with up to four hospital visits. Patients provided a $24 \mathrm{~h}$ sputum collection, for weighing at each visit. Spontaneous sputum was collected at the beginning of each visit; if insufficient sample was obtained, sputum was induced with hypertonic saline. Inflammatory markers were measured in dithiothreitol-processed sputum (total and differential cell counts, IL8 (and other cytokines), calprotectin, neutrophil elastase, myeloperoxidase and extracellular DNA). Blood was collected at each visit for cytokines (IL1 $\beta$, IL6, IL8, IL10, IL12 (p40) and TNF $\alpha$ ) and calprotectin. Data are available from 189 patients at 655 visits. Adequate sputum for analysis was obtained at only $60 \%$ of visits. Sputum induction accounted for only $16 \%$ of adequate samples. Median and range for each detectable assay are shown below. Serum cytokines IL1 $\beta$, IL10, IL12 (p40) and TNF $\alpha$ were undetectable at each visit, and IL6 was only detectable in $17 \%$ of samples. To assess intra-individual variability the coefficient of variation of results across each visit for each patient is presented. Both sputum and serum assays showed a large range of results at each visit, but the variation for each individual was much higher than the ideal $10 \%$. Serum assays were not able to discriminate between CF and non-CF, apart from calprotectin (CF 10.1 $(0.8-72.5)$ vs non-CF $0.40(0.2-1.12) \mathrm{p}<0.001)$. Due to the difficulty in obtaining sputum samples reliably and the large variability of results between visits in these stable patients, we consider it unlikely that a change due to a new therapy would be detectable. As such, we are not considering sputum inflammatory markers as primary or secondary efficacy endpoints in our multidose gene 